\title{
Revisitando algunas claves de la novela histórica del siglo XX
}

\author{
Re-visiting something keys of the Latin-American \\ historical novel
}

\section{Biviana Hernández O.}

\author{
Universidad Austral de Chile. Valdivia, Chile
}

biviana.hernandez@postgrado.uach.cl

\section{RESUMEN}

El presente artículo se concentra en una novela clásica de la narrativa histórica latinoamericana, El arpa y la sombra de Alejo Carpentier, a fin de explorar las relaciones que ella entabla con las concepciones modernas de la historiografía, que conciben el hecho histórico como relato o discurso, en tanto que su escritura como trama o narración; de donde trataremos de resaltar cómo historia y ficción construyen un diálogo nutricio para la elaboración de una cierta poética, crítica y reflexiva, de la historia.

Palabras claves: Nueva novela histórica, historia, historiografía, heteroglosia, ficcionalización.

\begin{abstract}
This article focuses on a classic novel of Latin American historical narrative, El arpa y la sombra by Alejo Carpentier, to explore the relationships that she established with the modern conceptions of historiography, who conceive of historical fact as story or speech, while his writing as narrative, of where we will highlight how history and fiction to construct a dialogue nurturing for the development of a certain poetic, critical and reflective of the story.
\end{abstract}

Keywords: New historic novel, history, historiography, heteroglossia, fictionalization.

Recibido: 24-09-2010. Aceptado: 30-11-2010. 


\section{PRESENTACIÓN}

Toda vez que el propósito fundamental de la nueva narrativa histórica consiste en ofrecer una relectura crítica del pasado, conforme distinto tipo de fuentes, documentos y registros, ya de índole historiográfica y literaria, nos referiremos aquí a una reconstrucción que supone tanto el conocimiento de aquéllos como también su distorsión, esto es, una "versión" de los hechos históricos, que si bien manipula conscientemente algunos de ellos, recrea los esenciales tanto en el aspecto cronológico como geográfico.

El presente artículo revisa la ficcionalización de Cristóbal Colón en una de las obras clásicas de la nueva novela histórica: El arpa y la sombra (1998) [1979], examinando previamente algunas de las ideas provenientes de la tradición de la novela histórica misma, como del discurso de la historiografía moderna, que nos permitirán acceder a una comprensión más amplia, compleja y, sobre todo, democrática de la historia.

El propósito de este análisis es determinar, por una parte, cuál es la versión que se construye del personaje histórico a través de la heteroglosia, categoría que en la novela corresponde a la estructura fragmentada del relato, mediante la imbricación de varios tipos de narradores, que fundamentan el carácter ideológico desmitificador de la figura histórica oficial de Colón; y, por otra, de qué manera en ella se reinterpretan los acontecimientos del así llamado descubrimiento de América, en tanto proceso de reflexión acerca de uno de los acontecimientos con que se inició una convivencia, que hasta el día de hoy no ha dejado de ser tortuosa entre las dos culturas de las que deriva la nuestra.

\section{UN GUIÑO DESDE LA HISTORIOGRAFÍA}

Considerando que los relatos constituyen el contexto natural donde los acontecimientos adquieren significación histórica, diremos que el contenido discursivo de toda narración de esta naturaleza se refiere a algo que sólo puede ser elaborado dentro de los márgenes de su "retórica", si pensamos que un mismo acontecimiento tendrá una significación diferente de acuerdo con el relato en que se sitúe o, dicho de otro modo, "de acuerdo con qué diferentes conjuntos de acontecimientos posteriores pueda estar conectado" (Danto, 1989: 45). Desde esta perspectiva, historiadores sociales y filósofos de la historia, como Marc Bloch, Jacques Le Goff y Hayden White, han 
especulado acerca de los aspectos fundamentales de esta ciencia, sometiendo a crítica la noción de hecho, acontecimiento y pasado históricos, así como el valor de los documentos y testimonios, tanto como la posibilidad de alcanzar un conocimiento objetivo del pasado. Reflexiones que arrancan de la sospecha de que los historiadores no han transmitido con fidelidad los hechos del pasado, cuando los habrían sometido a una serie de manipulaciones que modificarían su sentido original. $\mathrm{Al}$ respecto, interesante resulta la observación de White (2003), en el momento que afirma que una vez reconstruidos los acontecimientos, el historiador debe narrarlos conforme la lógica de un tramado, esto es, un esquema de narración que otorga a los hechos un carácter culturalmente aceptado. Así lo entiende el teórico, especificando que esta trama se define como la manera en que una secuencia de sucesos organizados se revela de manera gradual como un relato de cierto tipo particular, ya como metáfora, metonimia, sinécdoque o ironía; modos que definirían la naturaleza retórica del texto histórico y, en tanto que tal, como una ficción verbal, cuyos contenidos serían tanto inventados como encontrados, y cuyas formas tendrían más en común con sus homólogas en la literatura que en las ciencias.

Así las cosas, los historiadores tornarían inteligibles un conjunto de hechos, al organizarlos de acuerdo con una trama en que adquieren coherencia, y a partir de la cual interpretarían los acontecimientos siguiendo un esquema lógico, que permite instaurar el orden en el pasado y reducir el rol del azar, afín de tranquilizar a los lectores y hacerles creer que el mundo en el que viven se ha constituido de manera coherente, al estar regido por leyes racionales. No obstante lo anterior, es necesario advertir que White no considera que la historia sea un género literario. Su perspectiva apunta más bien a plantear que, por un lado, el conocimiento del pasado progresa, en circunstancias que historiadores y filósofos de la historia se han percatado de la naturaleza esencialmente provisional y contingente de las representaciones históricas, y de que éstas son susceptibles de una revisión infinita a la luz de una nueva evidencia o de una conceptualización más sofisticada de los problemas; y por otro, el hecho de que "la" historia (o su discurso, más bien) es un tipo de conocimiento sometido a criterios de veracidad, en la medida en que los acontecimientos que en ella se narran son reconstruidos a partir de documentos históricos y fuentes documentales, que permiten corroborar su mayor o menor grado de certitud. Así, aunque el historiador utilice el lenguaje figurativo de la ficción, en ningún caso será pretexto para construir antojadizamente los elementos de su relato. 


\section{BREVE RECORRIDO POR LA TRADICIÓN DE LA NOVELA HISTÓRICA}

En relación con el surgimiento de la novela hispanoamericana contemporánea, y tal como ha ocurrido con otros fenómenos literarios, la nueva novela histórica no implica un movimiento programático que contara con manifiestos y adherentes reconocidos, sino más bien una tendencia detectable en la novelística hispanoamericana de las últimas décadas del siglo XX. De hecho, Seymour Menton (1993) y María C. Pons (1996) coinciden en señalar que el primer indicio de su existencia fue simplemente el notorio aumento del número de novelas históricas publicadas, después de un largo período en que habían aparecido muy pocas. Tratándose de una construcción conceptual efectuada por estudiosos, que han sintetizado las características fundamentales y recurrentes de un conjunto de novelas surgidas entre 1979 y 1992 (según los registros específicos de Menton).

$Y$ en la medida en que este conjunto supondría elementos que las diferencian de las novelas históricas precedentes o "tradicionales", emplazaría una suerte de renovación radical de lo que Pons denomina el género $^{1}$ de la novela histórica, a raíz de lo cual la autora sostiene que si bien éstas presentan variaciones con respecto a su modelo tradicional, siguen perteneciendo a este género. Así las cosas, hemos de considerar que la nueva novela histórica expresa una relación de continuidad-discontinuidad, en lo que respecta al género histórico, motivo por el cual se hace necesario, al estudiarla, contemplar al menos dos aspectos fundamentales: a) cuáles son los elementos de las novelas correspondientes a este fenómeno literario que permiten sostener que pertenecen al género histórico; y b) cuáles son aquellos que las diferencian de las novelas históricas que las preceden.

Lo que está claro es que tratamos con un tipo de discurso literario, que se opone al realismo de la novela costumbrista y de la novela histórica decimonónica, al renunciar a la fidelidad de los documentos históricos, cuanto a la confianza en una voz oficial que determine la verdad de la historia; discurso que echaría mano, de acuerdo con este propósito, de nuevos sentidos para

\footnotetext{
${ }^{1}$ Éste se define como una institución sociocultural conformada por una serie de convenciones, en tanto prácticas de lectura y escritura que llegan a ser una costumbre. "Entendemos por convenciones del género a acuerdos tácitos, aquellas prácticas que por su recurrencia devienen costumbre aceptada o tradición [...] y que conforman un sistema de lugares comunes o conocimiento compartido [...] Estas convenciones no son fijas, sino que se modifican a lo largo del tiempo" (Pons, 1996: 44).
} 
la verosimilitud ficcional y para la interpretación misma de la historia. De allí que los novelistas latinoamericanos que representan esta tendencia, siguiendo a Diógenes Fajardo (1999), practiquen la reescritura ficcionalizada del discurso histórico oficial, con el claro propósito de ofrecer al lector la ficcionalización de los ya más de 500 años de vida histórica y de producción discursiva de Nuestra América.

$\mathrm{Si}$ en ese constructo que es Latinoamérica ha persistido a lo largo de todo el siglo XIX una novela histórica, en relación con la existencia de un género de esta naturaleza, cuya renovación ocurriría en la segunda mitad del siglo $\mathrm{XX}$, revisemos las características que en este periodo permitirían definirla como tal:

a) El rol que el pasado histórico juega en la ficción novelesca hace que lo individual se subordine a lo colectivo. Esto significa que las vidas personales son determinadas por el acontecer histórico, de forma tal que el devenir temporal adquiere el carácter de inacabado, no sólo en el sentido de que transcurre, sino también en que lo pasado puede modificarse al ser reinterpretado desde el presente, apareciendo la vida de los hombres como un acontecer dentro de otro que lo supera y determina.

b) Se ficcionalizan aquellos eventos o figuras históricas que han afectado el desarrollo posterior de los acontecimientos de un determinado grupo social y que forman parte del acervo común, ya sea porque aparezcan en los documentos históricos o porque perduren en la memoria colectiva del grupo social.

c) Y la historia se concibe como construcción discursiva, esto es, como un relato cuya narrativa se elabora desde una determinada perspectiva cultural e ideológica, con base en hechos registrados como reales; supuesto que implica que el material histórico de la novela es previamente textualizado en el discurso historiográfico. De suerte que, al recurrir a él la novela, no se constituye en una representación discursiva de los hechos históricos, cuanto de las versiones de los mismos, esto es, en una versión de las versiones de los hechos materiales.

Es sobre estas características esenciales que la novela histórica de fines de siglo XX en América Latina habría establecido algunas modificaciones respecto de la novela histórica tradicional, propias de sus condiciones de producción, que no justificarían, según Pons, el calificarla como un nuevo género de escritura narrativa, como asevera S. Menton. 
Cabe señalar que en la novela histórica tradicional se apreciaba una actitud de confianza hacia el discurso histórico; novela que, en cuanto género, comenzaría a desarrollarse después de la Independencia, por lo que su primera función habría sido la de crear una conciencia nacional en países que recién se estaban organizando. Pons ratifica esta idea al sostener que la indagación en el pasado de la novela histórica latinoamericana representaba una búsqueda de respuestas sobre la identidad de las nuevas naciones, y un reconocerse dentro de un proceso poco claro y de gran trascendencia histórica, como fue el de la postindependencia. Mas, aunque en algunas novelas se cuestionase la historia, esto no implicaba que los autores cuestionaran conscientemente la historiografía en cuanto forma de conocimiento y, menos aún, en cuanto forma de poder:

Sin contar con los intereses creados en tales cuestionamientos, estas novelas históricas asumen más bien una posición didáctica y de complemento de la historiografía. Además, entonces se consideraba que la Verdad de la Historia yacía fuera del texto (y de toda narrativa) y que era posible transmitirla a través de la novela histórica (Pons, 1996: 86).

Esta actitud de confianza, después de numerosas transformaciones, cambiaría sustancialmente con la nueva narrativa histórica, en circunstancias que en ella primó el interés de cuestionar explícitamente la supuesta veracidad de los textos históricos oficiales:

En términos generales, la reciente producción de novelas históricas se caracteriza por la relectura crítica y desmitificadora del pasado a través de la reescritura de la Historia. Esta reescritura incorpora, más allá de los hechos históricos mismos, una explícita desconfianza hacia el discurso historiográfico en su producción de las versiones oficiales de la historia (Pons, 1996: 16).

$\mathrm{Y}$ es frente a dicho cuestionamiento que emerge la posibilidad de preguntarse hasta qué punto las narraciones históricas -en el campo de la historiografía tradicional- no distorsionan los acontecimientos al introducir inteligibilidad, continuidad y orden en lo que, por naturaleza, es discontinuo y contingente. Jorge Peña Vial (2002) reflexiona sobre el particular, arguyendo que los hechos (re)presentados en una narrativa histórica se organizan mediante artificios lingüísticos, que definen el tratamiento ideológico que 
los historiadores utilizan para seleccionar sus materiales; hecho que supone, tal como lo sugiere $\mathrm{H}$. White con la idea de tramado, que éstos estructuran los acontecimientos de acuerdo a relaciones causales y temporales, que no necesariamente reflejan el orden en que ocurrieron, dirigiéndose a un tipo particular de lector, usando un vocabulario específico, no raramente lleno de connotaciones y adoptando un posicionamiento de valor ante los eventos narrados. Operación que desmentiría la existencia de un discurso privilegiado para hablar de la verdad y el pasado. Antes bien, lo que ésta propone es que los recursos lingüísticos de expresión están involucrados constitutivamente en todo discurso, que resisten cualquier pretensión de referencia y clara determinación de los hechos. En consecuencia, conscientes de que los hechos históricos registrados no coinciden necesariamente con los acontecimientos, los novelistas cultivadores de la novela histórica habrían cuestionado los textos que han formado nuestra percepción acerca de personajes y acontecimientos "fundamentales", siguiendo en ello a los historiadores y filósofos de la historia, que han reflexionado acerca de las características de su propia disciplina.

Y es este escenario el que permitirá a la nueva novela histórica dar cuenta de la revisión del discurso(s) de la historia, así como de la impugnación a sus versiones oficiales, a través de una serie de estrategias discursivas, entre las que se cuenta la heteroglosia, correspondiente a la superposición de diferentes discursos y sujetos de dichos discursos en el texto; figura que remite a un criterio de multiplicidad discursiva, al revelar el uso consciente de distintos niveles y tipos de lenguaje, como un mecanismo que intenta recuperar, en última instancia, la capacidad reflexiva y esencialmente crítica de la escritura (Galindo 1999). La heteroglosia -equivalente al sentido polifónico dostoievskiano estudiado por Bajtín (1998)-, será fundamental aquí para entender de qué manera el relato en El arpa y la sombra, hace erosión al ir construyendo redes de significación que complejizan los sentidos del suceso y personaje histórico ficcionalizados.

En la novela, la imagen que se construye de Cristóbal Colón resulta ser el producto de una síntesis de perspectivas desde las cuales ha sido leído e interpretado su viaje de descubrimiento, toda vez que en ella se hacen presente voces narrativas, que ponen en cuestión la empresa colombina y la figura que de ella se ha atribuido a su protagonista; las que transitan desde un relato omnisciente a uno en primera persona, hasta converger en otro polifónico, en que se entrecruzan los dos anteriores. Es lo que analizaremos con más detalle en el siguiente apartado. 


\section{LA FICCIONALIZACIÓN DE LA FIGURA DE COLÓN EN EL ARPA Y LA SOMBRA}

En El arpa y la sombra se ficcionaliza la figura de Colón desde distintas estrategias discursivas, como la parodia, la polifonía, la anacronía y la metaficción, por mencionar sólo las más relevantes; las que se convocan de acuerdo con la convergencia de relatos y de narradores, coexistentes en una confrontación mutua. Aquí la ficcionalización del personaje histórico autoriza una representación paródica, en la oposición que el discurso literario expresa frente a las versiones oficiales del discurso historiográfico. De este modo, el relato que el mismo Colón construye de su viaje -en la segunda parte de la novela- es utilizado para desmontar la ejemplaridad de su itinerario; así como el relato final -mezcla de omnisciencia y dialogismo- sintetiza una perspectiva crítica y anatémica, que acentúa la derrota y frustración del mismo. Es, por lo tanto, a través de esta figura que se hace posible una imagen del personaje histórico ya como inversión de su modelo o arquetipo. Tratándose de una lectura donde la polifonía, el dialogismo y la carnavalización de la historia encuentran asidero en la estructura fragmentada del relato, así como en la perspectiva desmitificadora desde la cual los distintos narradores se aproximan a la figura del Colón histórico; narradores que complementan el relato en tanto que pre-texto para responder al propósito fundamental de la obra: discutir la virtual santidad de Colón, de acuerdo con las causas y motivos que éste tuvo para emprender su derrotero rumbo a América.

La heteroglosia se articula aquí por medio de una historia superpuesta a la historia o, si se quiere, imbricada en el texto, desarrollándose mediante tres grandes secuencias narrativas: El arpa, La mano y La sombra, las que imitan un crescendo, en el que cada una juega un rol preponderante en la configuración de las restantes. Así, El arpa constituye la causa: la posible beatificación del almirante. La mano, el acto: la hazaña de Colón relatada por él mismo, quien agobiado por el peso de su conciencia, de su revés u otro yo, necesita decirlo todo. Y La sombra, la consecuencia: ¿debería Colón, conocida su verdadera identidad, convertirse en un santo americano, de ecuménico culto y renombre ilustrado? El último relato aúna voces representantes de distintos puntos de vista acerca del mismo fenómeno: quién fue en realidad el hombre llamado Colón y qué lo motivó a tomar un rumbo desconocido hacia lo que él creía eran las indias orientales. Prevaleciendo, no obstante, la mirada de quien juzga su impostura e irreverencia, pues la idea de erigirlo santo se estrellará contra lo que fueron sus actos de extrema ambición e impiedad, sólo un voto a su favor y la postulación de su beatifi- 
cación es denegada.

La narración correspondiente a la primera parte de la novela, El arpa, a través de un narrador extradiegético, presenta dos temporalidades: a) el presente del Papa Pío Nono, quien se encuentra a punto de rubricar el documento de postulación a la categoría de santo de quien fuera el descubridor de América, y b) el viaje a Argentina y Chile de Giovanni María Mastaï (convertido en Pío IX), en 1823-4, a bordo del velero Colombia; enviado como asesor de una misión apostólica, para combatir la amenaza de los maestros de la "impiedad y el libertinaje", como llamaba a los filósofos ilustrados del viejo mundo.

Mientras que La mano corresponde a la narración hecha por el propio almirante, en un relato homodiegético, en el que también intervienen dos secuencias temporales: una, la del presente de Cristóbal Colón (narrador), quien se encuentra agonizando en Valladolid en espera de su confesor; y otra, la del presente de la historia referida por él, en que a través de su testimonio se traslada a 1492, para referir los hechos del descubrimiento mediante una dilatada confesión, en la que declara cuáles fueron las verdaderas motivaciones que tuvo para emprender su viaje; discurso en el que reiteradamente se acusa, queja, sentencia, retracta y arrepiente de haber hecho lo hecho:

Dentro de este cuerpo derribado por las fatigas y los achaques, está el yo de lo hondo, aún claro de mente, lúcido, memoriado y compendioso, testigo de portentos, sucio de flaquezas, promotor de escarmientos, arrepentido hoy de lo hecho ayer, angustiado ante sí mismo, sosegado ante los demás, a la vez medroso y rebelde, pecador por Divina voluntad, actor y espectador, juez y parte, abogado de sí mismo ante el Tribunal de Suprema Instancia [...] Y alzar las manos y clamar [...] sentenciar y apelar, alcanzar las últimas instancias de un juicio donde, en fin de cuentas, estoy solo, solo con mi conciencia que mucho me acusa y mucho me absuelve (Carpentier, 1998: 51).

En esta parte de la novela se aprecia que el descubrimiento del nuevo mundo se funda en un principio, en esencia, lucrativo, esto es, desde el punto de vista de los intereses personales de Colón: "En cuanto a la gloria lograda por mi empresa, lo mismo me daba que ante el mundo con ella se adornara este u otro reino, con tal de que se me cumpliese en cuanto a honores personales y cabal participación en los beneficios logrados" (Carpentier, 1998: 72). Motivo que confirma cuando confiesa que sólo el oro guiaría, cual brújula mayor, el derrotero de sus andaduras; de donde la toma de posesión inescrupulosa de las islas descubiertas: 
$\mathrm{Y}$ ante tales reyes, si es que rey se puede llamar a quien anda poco menos que con las vergüenzas de fuera, hacía yo mis ceremonias acostumbradas: alzaba la bandera de mis monarcas cristianos, cortaba algunas ramas y hojas con mi espada, proclamaba por tres veces que tomaba posesión de la tierra en nombre de sus altezas, estando dispuesto -añadía- a responder con mi acero a quien me lo demandare (Carpentier, 1998: 110).

Desde esta perspectiva, se nos presenta un Colón sobrepasado por la codicia, hombre mísero de espíritu, obcecado y limitado por una enfermiza ambición. Características que explican de qué manera su falta de comprensión respecto a los indígenas, como objetos de conocimiento, le llevó a creer que éstos no tenían lengua, costumbres ni religión; en otras palabras, que carecían de toda manifestación cultural, percibiéndolos, a la postre, como seres inferiores, que debían ser convertidos a la civilización -que, por cierto él, como genuino europeo, representaba-mediante las instrucciones de la fe cristiana y la organización social.

Colón también confiesa que utilizó los evangelios y, por ende, el nombre de Cristo, sólo como excusa para continuar su empresa. Fue el mejor modo, declara, para justificarse ante los reyes. Luego, él mismo se dice avergonzado de ver la palabra "oro" tantas veces mencionada en la relación de su primer viaje: "Porque rutinario giro del lenguaje viene a ser el hecho de mencionar sólo catorce veces el nombre del Todopoderoso en una relación general donde las menciones del oro pasan de doscientas" (Carpentier, 1998: 113). Confesando, de paso, que se valió de la frase "Nuestro Señor" como una apócrifa seudodevoción a la que recurría cada vez que necesitaba encubrir su obsesión de hallar el preciado metal. Sin embargo, viendo abortada la posibilidad de evangelizar a los nativos, decidirá emprender un nuevo negocio, cual es el de comerciar esclavos americanos en Europa: "La solución a este grave problema, que no puede dejar indiferente a la iglesia, está en trasladarlos a España en calidad de esclavos. He dicho: de esclavos [...] Ya que no doy con el oro, pienso yo, puede el oro ser sustituido por la irremplazable energía de la carne humana" (Carpentier, 1998: 130-131). Mas, en cuanto la reina Isabel es informada de semejante proyecto, enviará una orden prohibiéndole ponerlo en ejecución, de manera tal que, una vez más, el almirante asistirá al rotundo fracaso de su negocio:

¡Se me venía abajo el único negocio fructífero que, para compensar la carencia de oro y especias, se me hubiese ocurrido. ¡En este segundo regreso, que había imaginado glorioso, me veía arruinado, desacreditado, desau- 
torizado, desaprobado por sus altezas y hasta llamado embaucador por el pueblo que ayer me aclamaba! (Carpentier, 1998: 136).

Y a la postre, no encontrando oro ni especias, sabiéndose derrotado en la consecución de al menos un triunfo moral, decidirá reemplazar el oro de Indias y el mercado de esclavos, la carne de Indias, por palabras, "grandes, hermosas, enjundiosas, jugosas, ricas palabras, llevadas en brillante cortejo de sabios", creando para sí, autoinducidamente, la ilusión y hasta la convicción de que encontró el auténtico Paraíso Terrenal, pues necesitaba justificarse y, de algún modo, también resignarse sintiéndose un hombre predestinado, único y necesario para la humanidad; éste sería, si acaso, el premio de consuelo por el esfuerzo (y fracaso) invertido en toda la empresa.

Mientras que en La sombra aparecerá el espíritu de Colón, el invisible, a la espera de su juicio final, instancia en que se determinará si será considerado un héroe sublime o un simple ser humano sujeto a todas las flaquezas de su condición. El juicio se realiza a través de la representación de un Auto Sacramental, en el que una serie de personalidades (también espíritus), escritores y filósofos, entre ellos, León Bloy, José Baldi, Bartolomé de las Casas, Julio Verne, Víctor Hugo, Alfonso de Lamartine, entre otros, discuten el destino del almirante, conforme los dos cargos que se le imputan: el primero, de concubinato; el segundo, de haber iniciado el comercio de esclavos. Resuelto el juicio $-y$ pese a la apología que de él hicieron muchos de sus panegiristas- obtiene sólo un voto a su favor, razón por la cual la postulación de su beatificación será rechazada.

Esta parte de la novela adquiere los rasgos que Menton describe como conceptos bajtinianos de lo dialógico, polifónico y carnavalesco, en la medida en que los personajes que participan en ella no sólo son completamente anacrónicos, sino que, simultáneamente, hacen uso de la palabra para exponer su visión acerca del personaje histórico, haciendo que el relato, dentro de sí mismo, sea mucho más heteroglósico que los anteriores. Aquí aparece un narrador extradiegético, similar al de la primera parte de la novela, pero que concede la palabra a otros sujetos para discutir la causa del postulado Colón. Así, por ejemplo, León Bloy, defensor de la causa, sostiene: "pienso en Moisés, porque Colón es revelador de la Creación, reparte el mundo entre los reyes de la tierra, habla a Dios en la Tempestad, y los resultados de sus plegarias son el patrimonio de todo el género humano" (Carpentier, 1998: 161). En tanto que Julio Verne, opositor de la misma, opina: "por este viaje, el viejo mundo asumía la responsabilidad de la educación moral y política del nuevo mundo. ¿Pero, acaso estaba a la altura de esa tarea (Colón), 
con tantas ideas estrechas como acarreaba, sus impulsos semi-bárbaros y sus odios religiosos...?" (Carpentier, 1998: 166). Mientras que el mismo acusado intervendrá en el relato oponiendo su versión a las de sus acusadores:

Hay normas de la fidelidad caballeresca que jamás entenderán esos mediocres leguleyos que ahora me culparon de amancebador, fornicador y no sé cuántas cosas más... Si no hubiese alentado el ideal que en mí llevaba, me habría ayuntado con indias [...] como hicieron tantos y tantos que me acompañaron en mis descubrimientos. Y eso, eso, jamás podrán decirlo de mí, por más que revuelvan papeles viejos, escudriñen en archivos, o presten oídos a las infamias sobre mí propaladas por los Martín Pinzón, Juan de la Cosa, Rodrigo de Triana, y otros bellacos encarnizados en mancillar mi memoria (Carpentier, 1998: 177).

Conforme lo anterior, diremos que la heteroglosia pone en cuestión el descubrimiento de América mediante la discusión, por una parte, de una idea: la de canonizar a Colón; y, por otra, a través del significado que el propio almirante le otorgó a sus actos una vez llegado a nuestro continente. De este modo, La mano no sólo reinterpreta su testimonio, contratexto de su Diario, sino que, además, estimula reflexionar respecto a las causas que promovieron en él su comportamiento hacia los pueblos nativos. Y si bien Colón se adjudica para sí mismo valores como el egoísmo y la ambición, no deja de percibirse como un hombre complejo y contradictorio, consciente de que su ser esconde otros que, en ocasiones, lo ocultan y, en otras, descubren; teniendo claro, además -en una reflexión metaficcional- que las palabras que dan vida a un relato no reflejarán nunca la realidad:

Y habrá que decirlo todo. Todo, pero todo. Entregarme en palabras y decir mucho más de lo que quisiera decir-porque a menudo el hacer necesita de impulsos, de arrestos, de excesos (admito la palabra) que mal se avienen, hecho lo hecho [...], con las palabras que, a la postre [...], inscriben un nombre en el mármol de los siglos (Carpentier, 1998: 49).

Valga citar aquí Vigilia del Almirante (1992), de Augusto Roa Bastos, a propósito de los comentarios que efectúa el narrador en torno a la propia ficción o, si se quiere, respecto del modo como se ha construido el discurso de la novela en relación con el de la historia. Al principio, en un breve texto que la precede y que funciona a modo de prólogo, Roa Bastos define la novela como un relato de ficción impura, o mixta, oscilante entre la realidad de 
la fábula y la fábula de la historia; y la caracteriza por defecto, señalando que es heterodoxa, ahistórica, acaso antihistórica, antimaniquea, lejos de la parodia y del pastiche, del anatema y de la hagiografía. Proponiendo, así, una manera atípica de entender los conceptos de realidad y ficción, al sugerir que la historia puede ser una fábula y que la fábula puede referirse a la realidad, contenerla o, bien, representarla. Perspectiva desde la que argumenta que la historia de Colón ha sido escrita ${ }^{2}$ desde una interpretación de los hechos, es decir, mediante un mecanismo que les confiere orden y explicación a los sucesos; lo cual habría inducido a sus autores a suprimir, inventar y tergiversar acontecimientos, de forma tal que lo narrado no podría, de ninguna manera, coincidir o identificarse con lo real. Al final del capítulo IX, esta crítica se amplía a la totalidad de la práctica historiográfica, con palabras que se asemejan a otras escritas por Hayden White:

El historiador científico siempre debe hablar de otro y en tercera persona. El yo le está vedado. Los historiadores son, de hecho, 'restauradores' de hechos. A partir de documentos reales, fabrican la ficción de teorías interpretativas semejantes a las 'historias' y a los diagnósticos clínicos sobre la mente humana. ¿Y son menos caóticos e indescifrables los hechos, llamados 'históricos', que los inescrutables laberintos de la mente? (Roa Bastos, 1992: 80).

$\mathrm{Y}$ a otras de Peter Burke, en el momento en que postula que los narradores históricos -entiéndase, historiadores- necesitan encontrar una manera de hacerse visibles en sus relatos, no por complacencia consigo mismos, cuanto por advertir al lector que, por un lado, no son omniscientes o imparciales frente a los hechos que estudian, y, por otro, que sus versiones de los hechos tan sólo suman un número más al registro vario de posibilidades de interpretación histórica; destacando, en este sentido, la idea de que el historiador no pretende conocer y predecir como simple observador, sino que adopta el punto de vista de un sujeto que participa, delibera y sopesa respecto de sus fuentes y materiales:

Modelo que responde a la voluntad de mostrar que la actividad de re-pensar desarrollada por el historiador no tiene porqué identificarse con alguna misteriosa e intuitiva capacidad de re-vivir los estados de conciencia del

${ }^{2}$ En ella se critican las siguientes obras: Historia de las Indias, de Fray Bartolomé de Las Casas; Vida del Almirante don Cristóbal Colón, de Hernando de Colón, hijo de Cristóbal; y Décadas del Orbe Nuevo, de Pedro Mártir de Anglería. 
agente pasado, sino que tiene su propia lógica y, por tanto, cierto carácter explicativo (Danto, 1989: 17-19).

Así las cosas, diremos junto al teórico, que el discurso como propiedad y dominio de un sujeto reflexivo y pensante (novelista o historiador), organiza al tiempo que interpreta el material histórico, de suerte que el producto de esas operaciones adopte la forma de un tipo de prosa, que elabora significados de función explicativa, y, en cuanto que tal, no más una reflexión impersonal que indefectiblemente subjetiva, "en el doble sentido de ser el marco en cuyo seno podemos autorrepresentarnos y, al mismo tiempo, marco en el cual el historiador no es espectador sino partícipe" (Danto, 1989: 27).

Por otra parte, evidenciando en la novela cuáles son algunas de las distorsiones en que pueden incurrir los historiadores, Roa Bastos fundamenta, a través de reflexiones metaficcionales, el aporte que la literatura y, en general, la ficción puede hacer a la comprensión de los hechos y personajes históricos, afirmando que las historias fingidas abren la imaginación al espectro incalculable del azar en el pasado como en el futuro, debido a que la literatura acepta una dimensión de la realidad, el azar, que la historia, conforme la necesidad de proveer explicaciones, es decir, de volver inteligibles los acontecimientos, intenta eliminar. En ello radicaría su mayor capacidad para descubrir las leyes que rigen la realidad, si es que las hay.

Vigilia del Almirante propone, entonces, no pensar la historia y la literatura desde la dicotomía realidad/ficción, ya que en ambas la imaginación jugaría un rol fundamental; apuesta, más bien, por entender que historiografía y literatura son géneros de ficción mixta, motivo por el cual no habría por qué pensar que las narraciones literarias que se ocupan de acontecimientos históricos serán menos verdaderas que las narraciones que pretendan ser históricas y, por tanto, exactas. El uso retórico del lenguaje convierte a las primeras en alegorías de las que tanto ficción como realidad forman parte, vale decir, supone que junto a la historia narrada existe otra, que el lector ha de develar, con lo cual las posibilidades de interpretación aumentan, a diferencia de lo que ocurre en la historiografía tradicional, donde el autor entrega todas las explicaciones que se necesitan, o, al menos, pretende que así sea. Así se explicita en la novela al inquirir:

¿Cómo optar entre hechos imaginados y hechos documentados? ¿No se complementan acaso en sus posiciones y contradicciones, en sus respectivas y opuestas naturalezas? ¿Se excluyen y anulan el rigor científico y la imaginación simbólica y alegórica? No, sino que son dos caminos dife- 
rentes, dos maneras distintas de concebir el mundo y de expresarlo (Roa Bastos, 1992: 66).

Después de la digresión, podemos afirmar que en El arpa y la sombra nos encontramos con la representación de un Colón irreverente e inescrupuloso, plenamente lúcido, aun cuando su lucidez, por instantes, se convirtiera en delirio; representación donde la posibilidad de erigirlo santo termina siendo un absurdo, por cuanto tras su versión de los hechos -en La mano- resulta descabellado que en su juicio final se apruebe la apertura del proceso de su beatificación. En este sentido, la novela expresa una relación de causalidad que se establece narrativamente no sólo entre sus tres relatos, sino también en que la figura de Colón, aun cuando sea presentada desde distintas perspectivas, termina siendo una sola: la del hombre déspota y ambicioso, que justificó sus fines a costa de tortura y esclavitud para los indígenas americanos, puesto que su único objetivo era acumular riquezas para su propio disfrute.

Cada parte de la novela explica las otras, al tiempo que influye y determina su interpretación, y si bien es posible leerlas, cada una, desde una perspectiva que por sí misma va trazando una cierta imagen de Colón, es su íntima relación la que conlleva la comprensión del personaje como producto de las relaciones entre la idea de erigirlo santo (El arpa), los hechos del descubrimiento que él mismo reconstruye en su relato (La mano) y la resolución final que desaprueba su virtual santificación (La sombra). Dicha relación es la que induce, en última instancia, a aceptar una versión que se corresponde con las características con que el mismo Colón se autorreconoce durante su confesión. Ello hace que otras perspectivas o versiones desde las cuales es posible entenderlo, entre ellas la de su santidad o las que se discuten en su juicio final: su condición de enviado por la divinidad, su capacidad de obrar milagros o ser revelador de la creación, sean descartadas por el lector.

\section{A MODO DE CONCLUSIÓN}

Diremos que la nueva novela histórica, en tanto que tendencia de la narrativa hispanoamericana del siglo XX, junto a las reflexiones provenientes de la nueva historia, tiene como objetivo último democratizar la historia, al rechazar la objetividad, la veracidad y la impersonalidad como criterios de producción textual o discursiva, devolviendo al lector la voluntad de inter- 
venir en su conocimiento, mediante la interpretación y reinterpretación de sus versiones, toda vez que éstas suponen un sujeto ideológico partícipe en la elaboración de sus narrativas. Tratándose de una tendencia que nos permite advertir que, así como los historiadores que han cuestionado los procedimientos de su propio oficio, no han llegado a la conclusión de que éste sea inevitablemente inexacto, los novelistas tampoco plantean que la verdad histórica sea imposible de conocer, que la historia sea un conocimiento condenado a la inexactitud o a ser utilizado con propósitos perversos, sino que lo que hacen es cuestionar la pretendida objetividad y proponen que no se trata de una verdad/falsedad sino de una interpretación o versión proponiendo elementos con los cuales se podrían construir otras nuevas y, por cierto, mejores. Es la apuesta de Carpentier en esta novela, epítome del género histórico.

\section{REFERENCIAS}

Bajtín, Mijail. 1998. Problemas de la poética de Dostoievski. México: Fondo de cultura económica.

Burke, Peter (ed.). 2003. Formas de hacer historia. Madrid: Alianza.

Carpentier, Alejo. 1998 [1979]. El arpa y la sombra. Madrid: Alianza.

Danto, Arthur. 1989. Historia y narración. Ensayos de filosofía analitica de la historia. Barcelona: Paidós.

Galindo, Oscar. 1999. "Nueva novela histórica hispanoamericana: una introducción”. Documentos Lingüisticos y Literarios 22, pp. 39-44.

Fajardo, Diógenes. 1999. Alli donde el aire cambia el color de las cosas. Bogotá: Escala.

Menton, Seymour. 1993. La nueva novela histórica de la América Latina, 1979-1992. México: Fondo de Cultura Económica.

Peña V., Jorge. 2002. La poética del tiempo. Ética y estética de la narración. Santiago de Chile: Universitaria.

Pons, María C. 1996. Memorias del olvido. La novela histórica de fines del siglo XX. Madrid: Siglo Veintiuno.

Roa Bastos, Augusto. 1992. Vigilia del Almirante. Buenos Aires: Sudamericana.

White, Hayden. 2003. El texto histórico como artefacto literario. Buenos Aires: Paidós. 